\title{
Public participation and transparency in water management
}

\author{
Lucia De Stefano', Nuria Hernández-Mora², \\ Elena López-Gunn', Bárbara Willaarts ${ }^{3}$ \& \\ Pedro Zorrilla-Miras ${ }^{4,5}$ \\ I Water Observatory of the Botín Foundation; Department of \\ Geodynamics, Complutense University of Madrid, Madrid, Spain \\ ${ }^{2}$ Founding Member, New Water Culture Foundation, Madrid, Spain \\ ${ }^{3}$ Water Observatory of the Botín Foundation; \\ CEIGRAM, Technical University of Madrid, Madrid, Spain \\ ${ }^{4}$ Autonomous University of Madrid, Madrid, Spain \\ ${ }^{5}$ Terrativa Sociedad Cooperativa, Madrid, Spain
}

\begin{abstract}
Public participation is broadly considered to have a positive impact on the quality of governance. Transparency is the first step in the public participation ladder since it implies that people have access to the necessary information to make informed contributions to decision-making. This chapter gives an overview of the main challenges for the Spanish water sector in terms of public participation in the water planning process of the Water Framework Directive (WFD), and presents results of an assessment of information transparency of the Spanish water authorities. Although the WFD has contributed to improving the situation, in Spain the tradition of public accessibility to data and public participation in water management decisions is still rather poor. In addition to making all relevant information publicly available, the most compelling challenge is possibly ensuring its reliability and consistency. Another key issue is making the information accessible to different target audiences by adapting it to their level of interest and technical capacity.
\end{abstract}

Keywords: public participation, transparency, accountability, Water Framework Directive, water planning process

\section{INTRODUCTION}

Public participation is a process where people -individuals, groups and organizationsare allowed to influence the outcome of plans and working processes that affect them. Thus, public participation is linked to public decision-making and, although there is still little conclusive evidence on its direct impacts on the policy process and political decision-making (Abelson \& Gauvin, 2006), it is broadly considered to have a positive impact on the quality of governance (López-Gunn, 2002). Transparency is the first step in the public participation ladder, since it implies that people have access to the necessary 
information to make informed contributions. The following steps, with an increasingly higher level of involvement of stakeholders, are consultation and active involvement.

This chapter gives an overview of the main challenges for the Spanish water sector in terms of public participation in water-related decisions. To do so, it first gives a brief overview of the opportunities (and related pitfalls) for regulated public participation in the water planning process, as provided by the Water Framework Directive (WFD). This is distinct from participation practices in decisions related to, for example, new water infrastructure design and approval, which are not analyzed in this chapter and are usually framed within standard environmental impact assessment procedures. Second, it focuses on the level of access to information in the Spanish water sector. It concludes with some considerations of the opportunities and threats for an improved public participation in water management planning.

\section{PUBLIC PARTICIPATION IN THE WFD PLANNING PROCESS}

The first international declaration that explicitly addresses the importance of public participation in water management dates back to January 1992, at the Dublin International Conference on Water and the Environment. In the same year, both the Rio Declaration and the Helsinki Convention on transboundary waters echoed the Dublin principles in relation to participation. In 1998, the Aarhus Convention ${ }^{1}$ transposed $^{2}$ the Rio principles relating to access to information into a legally binding document. By then, the European Union (EU) had already established minimum standards for public access to information and public participation in some environmental issues, but the Aarhus Convention extended the EU requirements, giving broader definitions of environmental information and public authority, and recognizing the right of citizens to turn to courts of justice when environmental rights are infringed.

Since 2000 a number of EU Directives have promoted several participatory elements, namely a Directive on public access to environmental information (Directive 2003/4/ EC); the partial transposition of the Aarhus Convention; a Directive for public participation when developing certain plans and programs relating to the environment (2003/35/ EC); and a Directive on the assessment of certain plans and programs on the environment (2001/42/EC). All these Directives complement the public participation provisions defined specifically for water resources planning and management under the WFD.

The WFD states that "to ensure the participation of the general public ${ }^{2} . .$. , it is necessary to provide proper information of planned measures and to report on progress with their implementation, with a view to the involvement of the general public before final decisions on the necessary measures are adopted" (WFD, Preambles 46). Specific legal provisions are then described in Article 14 of the WFD, which distinguishes three forms of public participation in the planning process (with an increasing level

1 The Convention on Access to Information, Public Participation in Decision-making and Access to Justice in Environmental Matters, or Aarhus Convention, was signed on June 25, 1998 and entered into force in 2001.

2 In this chapter in some cases we distinguish between the general public and stakeholders. By the first we mean society as a whole, by the second we mean individuals or organized groups of individuals that have a direct stake in decisions taken. 
of involvement): provision of information; consultation on draft planning documents; and active involvement. According to the Directive, the first two are to be ensured, while the latter should be encouraged.

Since the approval of the WFD several assessments on the quality of public participation have been undertaken both at EU and Spanish levels (for EU-wide evaluation see De Stefano \& Schmidt, 2012; for Spain see Espluga et al., 2011; Hernández-Mora \& Ballester, 2010; Espluga \& Subirats, 2008; FED, 2007). Drawing from the results of these assessments, it is possible to make a strengths-weaknesses-opportunities-threats analysis (SWOT) of participation in the framework of the WFD (Table 1).

Table 1 shows that, while the main strengths and opportunities are related to legal obligations to ensure participation and the long time frame of the planning process, human and political factors may hinder public participation efforts. In particular, the inertia to change current practices, as well as the complexity of the planning process, may create frustration and fatigue among stakeholders. Indeed, participation entails a difficult balance between representative democracy -where elected or appointed representatives have the task of making decisions- and the expectation by stakeholders to have an impact on policy making. The actual or perceived lack of impact of stakeholders' engagement may detract from the legitimacy of the participatory process or may eventually lead participants to withdraw from it. Moreover, the role of lobby groups -with explicit or vested interests in the decisions to be made- is ambivalent and can be difficult to manage, within and outside of regulated participatory processes. On one side, interest groups can help in widening the scope of the discussion and conveying widespread concerns to decision-makers. On the other side, however, and

Table I SWOT analysis of the WFD and its implementation process regarding public participation.

\begin{tabular}{|c|c|}
\hline Strengths & Weaknesses \\
\hline Legal obligation to encourage/ensure participation. & Poor participatory tradition in some countries. \\
\hline $\begin{array}{l}\text { Increased financial resources associated with the } \\
\text { water planning process. }\end{array}$ & Limited human and financial resources. \\
\hline $\begin{array}{l}\text { 3-step process, stimulating public and stakeholders } \\
\text { and managing their expectations. }\end{array}$ & Tight implementation schedule. \\
\hline \multirow{2}{*}{$\begin{array}{l}\text { Three planning cycles to gradually adjust } \\
\text { approaches and tools. }\end{array}$} & Technical complexity of the planning process. \\
\hline & $\begin{array}{l}\text { Inadequate national transposition of EU legal } \\
\text { requirements in some countries. }\end{array}$ \\
\hline Opportunities & Threats \\
\hline Aarhus Convention requirements. & Stakeholder fatigue and disillusionment. \\
\hline $\begin{array}{l}\text { EU Directive on access to environmental } \\
\text { information. }\end{array}$ & $\begin{array}{l}\text { Inertia of well-established planning processes } \\
\text { to adapt to more participatory approaches. }\end{array}$ \\
\hline $\begin{array}{l}\text { Support and input from research programs } \\
\text { and projects. }\end{array}$ & $\begin{array}{l}\text { Resistance of traditionally powerful lobbying } \\
\text { groups to the increase in transparency and } \\
\text { participation scope. }\end{array}$ \\
\hline \multirow[t]{2}{*}{ Increased credibility of public authorities. } & $\begin{array}{l}\text { Lack of political commitment to participation } \\
\text { processes and outcomes. }\end{array}$ \\
\hline & Budget cuts due to the EU economic crisis. \\
\hline
\end{tabular}

Source: Modified from De Stefano \& Schmidt (2012). 
depending on their lobbying effectiveness, they can shift the focus of decisions from the achievement of the common good to the support of a specific sector of society.

Participatory processes are also the fora where conflicts or tensions among uses and interests are expressed. This entails an opportunity to conciliate different interests and at times it can lead to a deadlock situation in the decision-making process.

\section{INFORMATION TRANSPARENCY}

Transparency is a core component of the so called second generation institutional reform, and it is increasingly associated with better socio-economic development, as well as with higher competitiveness and lower corruption, which ultimately can improve policy outcomes (Bellver \& Kaufmann, 2005). Transparency for example, can facilitate participation and collective action by stakeholders and is at the heart of water governance, fair allocation to users and sound incentives for efficient water use. Transparency in the work of public administration is considered to be the key in the fight against corruption in the public sector. It is also essential for an effective public participation, as only a well-informed public can effectively take part and actively contribute to public decision-making. Some authors distinguish between transparency OF governance and transparency FOR governance. The first relates to empowering society in observing "the actions either of regulators to whom they have delegated power or other powerful actors in society" (Mitchell, 2011), while the second refers to the disclosure of information by government as a means to influence the behaviour of corporations or other organizations. This section focuses on the first concept in the context of water management in Spain, and considers only access to information by the general public and interested parties. Nonetheless it is important to highlight that, in order to ensure real and full transparency, access to information must be accompanied by: 1) a guarantee about the quality and reliability of the information provided; 2) the opportunity of participating in the associated processes of decision-making; and 3) access to justice when the right to information or participation is not granted.

In Spain the concern about corruption in the public sector and the perceived lack of transparency has triggered several initiatives to improve transparency and accountability in public decision-making and the management of public resources. In 2008 Transparency International-Spain (TI Spain) developed an index of transparency for local authorities, which measures the degree of transparency in the functioning and operation of public administration at the municipal level, and is calculated on an annual basis, with public presentations to the press and wide distribution of the results. This was followed in 2010 by an index of transparency for Autonomous Communities (regional governments), also carried out by TI Spain ${ }^{3}$. The most recent and significant initiative is the proposed Law of Transparency, introduced by the newly elected conservative government in March 2012 as a key element in its effort to curb corruption and increase government legitimacy.

In the case of the water sector, in 2003 the New Culture of Water Foundation ${ }^{4}$ undertook a preliminary diagnosis of the nature of corruption and mismanagement in

3 For the methodology and results of these annual indexes see: [http://www.transparencia.org.es/].

4 Private not-for profit organization dedicated to advocacy, education and outreach on water policy and management (www.fnca.eu). 
the water sector in Spain (Martínez \& Brufao, 2006). The report included a discussion on limitations to the right to participation and access to environmental information. In 2010 TI Spain -with the support of a technical team formed by the authors of this chapter- developed the Index of Transparency in Water Management (from now on referred to as INTRAG, its Spanish acronym), an aggregate of 80 indicators aimed at assessing transparency in River Basin Organizations (RBOs) in Spain. INTRAG has been calculated for two years running (2010 and 2011) and the results are discussed in this chapter. It is worth noting that this is not an isolated initiative. In effect, the Spanish Association of Public Water and Sanitation Providers (AEOPAS) and the Institute of Fiscal Studies of the Spanish Ministry of Economy, developed in 2011 an assessment index for urban water providers that includes, among other issues, indicators for transparency and public participation in urban water resources management inspired in part by the INTRAG methodology.

\section{I Assessing transparency in the water sector}

When assessing the ease of access to information, at least two levels of transparency can be clearly distinguished: proactive information and access to information upon request. INTRAG focuses primarily on the first level of transparency. The second level is also very relevant for good governance, and in Spain it is still a pending issue. Despite the existence of a clear regulatory framework for access to environmental information, processes to actually obtain the requested information can be long and cumbersome.

INTRAG comprises a set of 80 indicators organized into six areas: Information about the RBO; Relationships with stakeholders and the public; Transparency in the planning process; Transparency on water use and management; Economic and financial transparency; and Transparency in contracts and tenders.

The calculation of the INTRAG index is based solely on information available in the websites of the evaluated RBOs. It is important to underline that INTRAG evaluates the presence or absence of information important for transparency in the management of water, and not the quality of that information (De Stefano et al., 2011). Too much information, or information presented in a way that is inaccessible or inappropriate to the needs and capabilities of the target audience, can also result in opacity. INTRAG focuses on the information available through the web pages of RBOs because it is accessible to the wider public and does not require direct access to managers and policy makers, which has traditionally limited access to information to organized stakeholders and pressure groups.

\subsection{INTRAG 2010 and $201 \mathrm{I}$}

The results obtained in the application of the INTRAG in 2010 and 2011 show that there is a clear need to improve transparency in water management in Spain ${ }^{5}$ (Figure 1). Indeed, in 2010 only seven out of fourteen RBOs evaluated obtained a

5 Each indicator may have two values: 0 (information not available) and 1 (information is available). Therefore the maximum achievable score for each RBO is 80 . In the final calculation of INTRAG this score is expressed in a scale of 100 for better communicability of the results. 

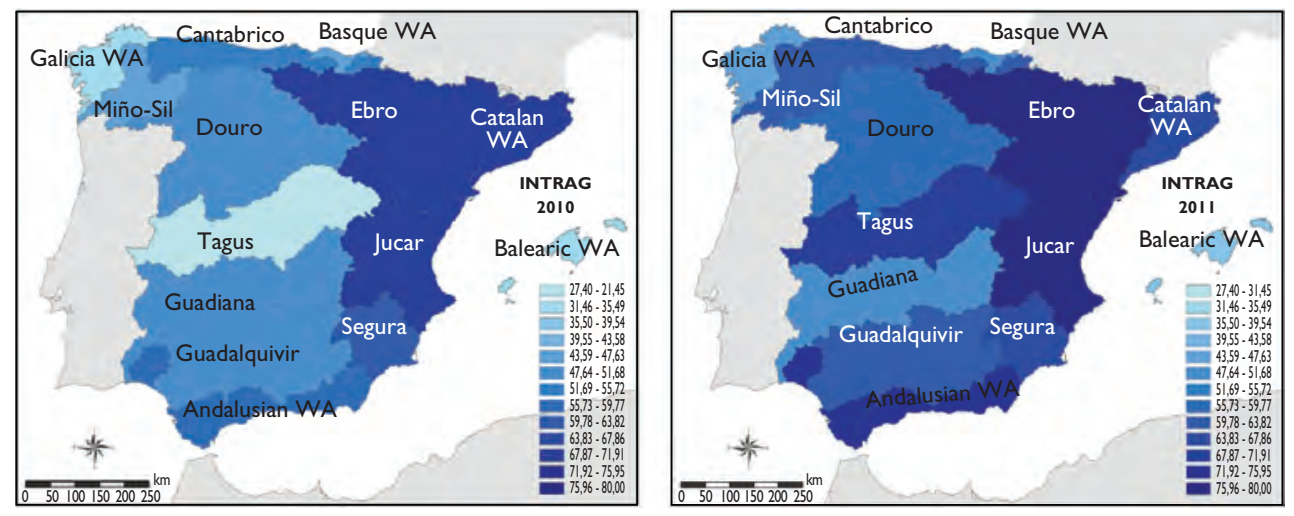

Figure I Overall scores of INTRAG 2010 and 20I I. (Source: Own elaboration with data from TI Spain [http://www.transparencia.org.es]).

total score higher than $50 \%$ of the maximum score attainable, with no RBO scoring more than $71 \%$. In 2011 the results improved slightly, with 11 RBOs obtaining a score higher than $50 \%$ and three scoring higher than $71 \%$.

Figure 1 shows the scores for the RBOs evaluated. The figure shows that, in both 2010 and 2011, the most transparent basin organizations were the Ebro and Júcar RBOs. The Catalan Water Agency achieved top marks in 2010 but received a lower score in 2011, after a new management changed policy priorities, among them budgetary cuts and a decreased emphasis on public participation and transparency. At the other end of the spectrum, the entities that have achieved the lowest overall scores both years were the Galician Water Agency and the Balearic Water Agency. The Tagus $\mathrm{RBO}$, on the other hand, evolved from a failing grade in $2010(27 \%)$ to a fourth position in 2011, also as a result of a change in the Presidency of the Agency and of an increased emphasis on governance and transparency. These results show that the ranking of a specific water authority can rapidly change if there is a restructuring of its webpage, which can respond to changes in top-down defined policy priorities. Below we focus on the overall picture to identify the main strengths and weaknesses in information transparency as detected by INTRAG 2010 and 2011.

The breakdown of results by thematic areas can be seen in Table 2 and shows that, for both years, there is a significant amount of information available about the organizational structure and legal context of the RBOs (Information about the RBO) and about the planning process underway in the context of the WFD (Transparency in the planning process).

The thematic areas relative to Relationships with the public and stakeholders and Transparency in contracts and tenders have a certain degree of transparency, but need to be enhanced. In the first area, it is important to improve transparency on the composition as well as on the content of the debates and deliberations of the councils, boards and committees that are a part of the RBO's decision-making bodies (Governing Boards, Water Councils, Competent Authorities Committees, etc.). Another area that needs improvement is the publication of annual statistics referring 
Table 2 Average scores of INTRAG 2010 and 2011 by thematic area.

\begin{tabular}{lll}
\hline Thematic area & Average score 2010 (\%) & Average score 20II (\%) \\
\hline Information about the River Basin Organisation & 72.0 & 85.7 \\
Relationships with the public and stakeholders & 58.0 & 56.1 \\
Transparency in the planning process & 88.0 & 79.9 \\
Transparency in water use and management & 32.0 & 47.0 \\
Economic and financial transparency & 35.0 & 43.8 \\
Transparency in contracts and tenders & 48.0 & 51.9 \\
Overall average & 51.2 & 59.6 \\
\hline
\end{tabular}

Source: TI Spain [http://www.transparencia.org.es].

to public requests for information from RBOs and their responses to those requests (an integral part of the legal right to information on environmental matters), or the publication of the RBOs' annual activity reports. For the area relative to contracts and tenders, there has been some improvement in 2011, but more information is still needed about modifications of projects, end-of-construction settlements and on the major contractors and suppliers of each Agency.

The largest deficiency in transparency is found in the areas of Transparency on water use and management and of Economic and financial transparency, although there has been some improvement between 2010 and 2011 (average scores increased from 32\% to $47 \%$ and from $35 \%$ to $43.8 \%$, respectively). In the first area there was a general deficiency of information on statistics of water use (updated information on existing water use permits, new permit requests and annual volumes extracted); information on compliance with existing regulations on water quality and environmental flows; and the legally required feasibility reports for new hydraulic infrastructures regulated under the public interest regime ${ }^{6}$. With regard to Economic and financial transparency there is generally little information available on: cost recovery for investments in new public hydraulic works; water tariffs and dues; financial relationships with water user communities and irrigator associations; and budget execution by the Agency.

\section{CHALLENGES FOR THE FUTURE}

The assessment of public participation in the Spanish water sector shows that, despite the presence of a favourable legal framework, it is still necessary to move from formal participation to real participation of the public and all interested parties in waterrelated decision-making processes (for more information see Hernández-Mora \& De Stefano, 2011). Information transparency is key to that. In general, INTRAG 2010 was positively received by the RBOs and there is evidence that their transparency is slowly improving. Nonetheless, there is still a long path ahead for having all the relevant information available online. For example, it is necessary to improve

6 The public interest regime or régimen de interés general is a legal concept that allows for preferential funding and fast tracking of the permitting process of public infrastructures. 
information on indicators relating to the economics and finance of RBOs because this kind of information is crucial to improving institutional credibility and public trust.

In addition to facilitating access to information, the Spanish water sector faces several challenges in terms of transparency. The most compelling challenge is possibly ensuring the reliability and the consistency of the information made available by public administrations. Another key issue is making the information accessible to different target audiences by adapting it to their level of interest and technical capacity. It is also important to create participatory processes that motivate and facilitate not only stakeholders, but also the general public to becoming involved in public decisionmaking regarding water management.

The WFD has contributed to increasing the quantity and quality of public participation and transparency in the Spanish water sector. The learning process of the first planning cycle (2009-2015) as well as the progressive activation of some sectors of civil society in relation to water are likely to set a fertile ground for an increased and improved participation in the future. A key consideration in this sense is that water managers should be aware that processes and practices applied in the first planning cycle of the WFD are a step forward but do not represent a catalogue of best practices. Therefore the results obtained from these processes are not an indicator of the potential of public participation as an integral part of public decision-making, but rather a starting point from which to draw lessons and make improvements in the future.

\section{REFERENCES}

Abelson, J. \& Gauvin, F.P. (2006). Assessing the Impacts of Public Participation: Concepts, Evidence and Policy Implications. Research Report P06. Public Involvement Network. Canadian Policy Research Networks.

Bellver, A. \& Kaufmann, D. (2005). Transparenting Transparency. Initial Empirics and Policy Applications. The World Bank.

De Stefano, L. \& Schmidt, G. (2012). Public participation and water management in the European Union: experiences and lessons learned. In: Cosens, B. (ed.), The Columbia River Treaty Revisited: Transboundary River Governance in the Face of Uncertainty. A Project of the Universities Consortium on Columbia River Governance. University Press, Oregon State, USA.

De Stefano, L.; Hernández-Mora, N.; López-Gunn, E.; Willaarts, B.; Zorrilla Miras, P. \& Llamas, M.R. (2011). Transparencia en la gestión del agua en España: fortalezas y debilidades [Transparency in water management in Spain: strengths and weaknesses]. In: HernándezMora, N. \& De Stefano, L. (coords.), Transparencia en la Gestión del Agua en España [Transparency in water management in Spain], SHAN Series no. 4, Botín Foundation. Available from: http://www.fundacionbotin.org/case-studies_publications_water-observatory_trendobservatory.htm [Accessed 31st May 2012].

Espluga, J. \& Subirats, J. (2008). Reflexiones sobre los procesos participativos en marcha [Considerations on the ongoing participatory processes]. In: Actas del VI Congreso Ibérico sobre Gestión y Planificación del Agua. New Water Culture, Bilbao, Spain. Available online from: http://www.fnca.eu/congresoiberico/documentos/p0403.pdf [Accessed 31st May 2012].

Espluga, J.; Ballester, A.; Hernández-Mora, N. \& Subirats, J. (2011). Participación pública e inercia institucional en la gestión del agua en España [Public participation and institutional intertia in water management in Spain]. Reis, 134, April-June 2011: 3-26. doi:10.5477/cis/ reis.134.3. 
FED (Fundación Ecología y Desarrollo) (2007). Percepciones y opiniones de 40 de los principales agentes de la sociedad civil sobre la implementación de la Directiva Marco del Agua y el proceso de participación en la Demarcación del Ebro [Perceptions and opinions of 40 of the main civil society actors about the implementation of the Water Framework Directive and the participation process in the Ebro River Basin District]. Ebro River Basin Authority. Available from: http://oph.chebro.es/DOCUMENTACION/DirectivaMarco/ParticipacionC iudadana/40agentes.pdf [Accessed 31st May 2012].

Hernandez-Mora, N. \& Ballester, A. (2010). Public participation and the role of social networks in the implementation of the Water Framework Directive in Spain. Ambientalia, Special Issue: Ten years of the Water Framework Directive: An Overview from Multiple Disciplines. Available online from: [http://www.ambientalia.org].

Hernández-Mora, N. \& De Stefano, L. (cords.) (2011). Transparencia en la Gestión del Agua en España [Transparency in water management in Spain]. SHAN Series no. 4, Botín Foundation. Available from: http://www.fundacionbotin.org/case-studies_publications_ water-observatory_trend-observatory.htm [Accessed 31st May 2012].

López-Gunn, E. (2002). La participación de los usuarios y de los ciudadanos en la gestión de las aguas subterráneas: el caso de Castilla-La Mancha [Users and citizens participation in groundwater management: the Castilla-La Mancha case]. Jornadas sobre presente y futuro del agua subterránea en España y la Directiva Marco Europea. Ponencia 7.2. Zaragoza, Spain. AIH-GE. Available from: http://www.aeuas.org/resources/pdf/gunn.pdf [Accessed 31st May 2012].

Martínez, J. \& Brufao, P. (2006). Aguas limpias, manos limpias: Corrupción e irregularidades en la gestión del agua en España [Clean waters, clean hands: corruption and misbehaviours in water management in Spain]. Ed. Bakeaz, Colección Nueva Cultura del Agua.

Mitchell, R.B. (2011). Transparency for governance: The mechanisms and effectiveness of disclosure-based and education-based transparency policies. Ecological Economics, 70(11): 1882-1890. 15 September 2011, Special Section - Earth System Governance: Accountability and Legitimacy. 
